\title{
Impact of Conflicts on Productivity at Workplace
}

\author{
Dr Bhakti Parashar ${ }^{1}$, Ravindra Sharma ${ }^{2}$ \\ ${ }^{1}$ Assistant Professor, VIT-Bhopal University, Bhopal, India, e-mail: sharma.bhakti@gmail.com \\ ${ }^{2}$ Assistant Professor Swami Rama Himalayan University, Dehradun, India, e-mail: ravindrasharma97@gmail.com
}

\begin{abstract}
Employee's productivity is the most important and pressurising issue in the organization which is now a days a very normal and natural part in this global competition with the differences in culture, values and ethics. As the world trade is operating under one umbrella people comes from different backgrounds and work style are taken together for shared business purposes, so conflict may take place in any type of association. Organizations generally tries to make their employees to work together and conflicts start when people with variety of workstyle, goals, motivations and process work together with different priorities. There can be many repercussions of such conflicts such as insults, non-cooperation, bullying, aggression and many a times fighting and harming other physically due to ego classes. People with such surroundings may be affected with stress even if they are not a part of that conflict because such conflicts create unhealthy working environment. Majority of people come with the solution that not to put those people in the same team who are creating conflicts, but this is the biggest misstate generally an organization does, because such decision may result in communication gap, lack of understanding, wrong perception. Neither we can separate people involved in conflict and let them stop communicating with each other nor can we leave them on their own because unresolved conflicts may lead to feeling of insult, hopelessness, dissatisfaction, unhappiness and so on. The extreme outcome of unresolved conflicts is work disruption, decrease productivity, project failure, absenteeism, turnover and termination.
\end{abstract}

However if resolved properly it may result in better understand, ideas, working conditions and relationship and finally increase in productivity and profitability. Thus, this paper attempts to find out the possible outcomes of conflicts on the productivity of an employee and what can be effective solution for such conflict for retention of employees and their productivity.

Index Terms-Employees, productivity, conflicts, workplace

\section{INTRODUCTION}

$\mathrm{W}$ ORKPLACE environment is one of the most significant factors now a days, when it comes to workplace specially private organization are giving special privilege to retaining talented employees, where the employer knows these talented employees are highly demanded in the market. In contrast adverse workplace environment creates negativity and decrease productivity of workers. Nevertheless conflict at workplace is unavoidable especially at large scale organizations, where if managed properly will give you substantial change and can put positivity and the sense of competitiveness among employees which may improve performance, which is very rare, because instead of giving stress at moderate level to employees to convert into eustress employer does not know when it has converted into distress, as there is a very thin line between estruses and distress. With this the confusion of getting positive impact of competitiveness and improvement in productivity employer generally ignore the workplace conflict and unintentionally conveys the message that inappropriate workplace behaviour and inadequate work performance is happily accepted in the organization. In addition to this, corporate culture has become so complex and complicated with the people of different culture, values, interest and expectations. By way of all this workplace complication generally the efficiency and productivity of employee's decreases and dissatisfaction, employees' turnover, adverse workplace environment, poor performance and frustration increases.

Conflict is a natural thing generally happened in most of the organization, it occurs when one person perceives his/her interest is being declined or opposed. There are basically two types of conflicts Vertical that is between different hierarchy levels whereas the Horizontal one occurs between the individual at the same level. Conflict can also be interpersonal or intrapersonal, when there is a conflict between two or individuals that is called interper-

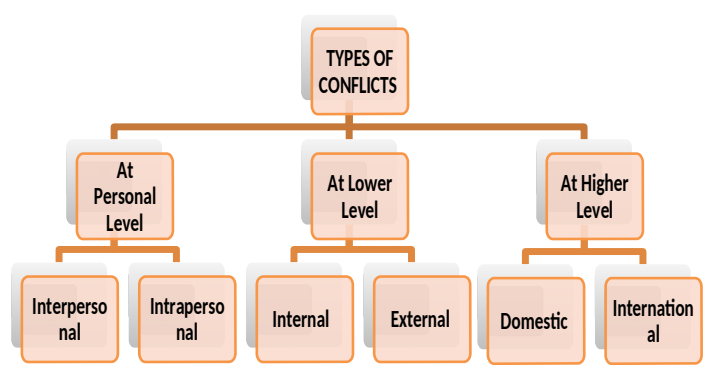

Fig. 1 Types of Conflict Source: - Authors own 
sonal and when it arises between one or two groups then that will be considered as intra-personal conflict. It may be internal or external and it may be at micro level or macro level. An internal conflict happens within the organizational people and external one takes place with the people or group outside the company. Similarly, a micro level or conflict at national level can be described when conflict arises with the people who resides within the domestic territory of the country, but when this conflict extended and reaches to international front or with foreign country people it will be called macro-level conflict or international conflict.

The above graph summarises the types of conflicts, where the conflicts start from interpersonal level and extended to international level if it is a multinational organization dealing with other countries as well.

Nowadays, business particularly a large scale one tries to hire people not with only good intelligent quotient but with emotional quotient as well. Since all organizational people knows very well the conflict very soon leads to non-productivity, negatively affect the performance of team, defame and ultimately loss to the company or may result to shut down.

Instead of giving distress, depression, frustration, loss of interest, hypertensive diseases to the employees due to ignorance of conflict at workplace which leads to the ultimate loss to the organization, one should look after the solution to get rid of such conflicts.

\section{REVIEW OF LITERATURE}

Knippen and Green(1999) says that the best possible way to tackle conflicts empirically is that one should follow six process that explains the conflict situation to others, asking the other party how he look into the conflict situation, reacting in the manner the other party looks into this situation. Combining these two and deciding how to resolve this problem of conflict and making commitment to resolve by summarizing action taken by each party to solve it and promising to be committed in future to continue resolving it which might arise.

Moore (2007) has correlated employee's performance with the performance criteria that has a set of standard for employees behaviour at workplace which include more of how an employee does the work than that of what is the employee's work Workers are evaluated on the basis of how good they are at their job measured with certain set of standards fixed by the employer. Performance of employees is basically related to the performance appraisal to compare employee's goal achievement with the set of standards.

Dontigney (2012) also favours that conflict may decline trust on the employer by employees that can slow or stop progress of project implementation, loss of trust and slow progress can be the negative impact .Consequently, customer dissatisfaction, failure in completing deadlines for delivering goods and services, fall in service quality will be ultimate outcome.

Rana, G., Sharma, R. (2017), organization culture play pivot role in managing conflict situation in an effective way in the organization.

Kelly (2012) opined that there is a need to acknowledge organisational conflicts and its existence along with opening the options for systematic solutions by business leaders. An adaptable organization should be encouraged which can copes efficiently with the dynamism in modern business. This is the most contemporary, functional view which treats organizational conflict as positive and productive force.

Sharma (2019) postulated that engaged employee are less involved in organizational conflict. Therefore organizations should ensure proper engagement of employees in workplace.

Rana (2017). Organizations have adopt multiple approaches to deal with workplace conflict. Efficient management control can also prove important in dealing with workplace conflict.

Olu OJO\& Adensubomi Dupe Abolade (2014) emphasised on the trailing and retraining of the employees in the field of conflict management which will help to create a healthy working environment. For that efficient and effective communication should always be there between all the employees at all level. It's the responsibility of management to make such policies which can ensure people that the conflict which occurs within the organization will be resolve with a fast pace.

Bellet, Clement and De Neve, Jan-Emmanuel and Ward, George (2019) analysed that employee's happiness is most important and more closely related to sales, there are so many extensive margins of happiness the frequency of workforce supply like attendance and breaktaking. The study concluded that if the employees at workplace are happy their productivity and efficiency will be more.

Rana G., Sharma R., Goel A.K. (2019), Effective conflict resolution mechanism in the organization improved business performance.

Rasool Faiz Samma, Maqbool Rashid, Samma Madeeha, Zhao Yan and Amna Anjum (2019) determined how an unhealthy toxic environment at workplace can directly and indirectly influence the employees productivity and may go to the extent of depression ,toxic workplace environment is inversely proportion to workers productivity because of multiple reasons like harassment, bullying, ostracism and incivility, all are the consequences of severe conflicts at workplace and due to which repercussion like insomnia, more absenteeism, social dysfunction, headaches, heart related health issues like blood pressure and diabetes are obvious.

Rana, G. and Sharma, R. (2019), said technology helps in minimizing work related conflicts as through 
technology work allocation can be done in a transparent way.

Eke John, Chika Ebere, Akintokunbo, Odunayo Oluwarotimi (2020):-Conflict can be constructive, but it has always been seen as evil, but the constructive one that is conflict management is a high point for any working environment. Conflict management in an organization can create a very good and conducive workplace environment which can be free from violence, resentment, incivility and can be prevented from financial, psychological or physical loss of employees and employer.

\section{REASONS BEHIND CONFILCT}

These days due to globalization and cut-throat competition employees productivity and performance is the priority of a standard organization which put lot of pressure on the employer as well as the employee which may end with distress and conflicts at workplace, a worker cannot work with good productivity under lot of pressure and definitely if he works with such circumstances will result in distress, conflicts and loss of productivity and ultimately he will leave such organization and a company will lose efficient, highly productive and talented employee as tolerance level is different from person to person.

Basic reasons behind conflicts at the work place can be:-

* Diversify values, customs, attitude personalities and perception is one of the common reason behind conflicts, people from same place, gender or religion makes their group on the basis of their compatibility and doesn't gel with other group.

* People with different needs, expectations and communication find difficulty working together in a team.

* Any organization tries to maximize their profit on the cost of minimizing cost and that can be possible by limiting the resources and time which makes worker tensed and stressed, with such circumstances employee generally loses temper and there are chances of vertical conflict.

* When some ambiguous kind of roles and responsibilities are given to employees, lot of confusion arises and conflicts too.

* Unclear administrative procedure and sometimes reward structure and decision making strategy makes organization's work culture more complicated and confusing.

\section{IMPACT OF CONFLICT}

If conflict at workplace continuously be ignored by the employer, it may lead to the serious problem and ultimately some serious outcomes company has to face. It is the responsibility of an HR to settle any kind of conflicts at initial level otherwise the whole blame will come to him by ignoring such conflicts. Some of the major impact of conflicts at workplace can be:-

* The first most impact is company's reputation which can be harmed by the people who are involved in the conflict and their conflict has not been resolved. When a company is in bad books, it's very difficult to find talented people to hire.

* Unsettled conflicts or the presence of conflict at workplace creates unnecessary tension and stress among the employees which affects their efficiency and productivity. People cannot work in such environment with full dedication and concentration.

* Biased resolution of conflicts create dissatisfaction among the employees besides loss in productivity and efficiency results in project failures, high absenteeism, loss of interest and ultimately loss of customers and profit.

* Unresolved conflicts often accomplish with frequent arguments and may be fight which creates negativity at workplace, even those who are not involved in the conflict may be affected from it.

* Poor communication and misunderstanding affects employees moral which demotivates them to continue with the present job, more employees turnover will happen with such conditions.

\section{SugGestions}

Workplace conflict first of all should not be taken lightly, if a person is well worse with good HR practices and supported by the higher level management people then the chances of conflicts at workplace is least. An organization must embark with HR policies which should be formulated in such a manner so that occurrence of conflict is minimized. Even though conflict occurs it should be resolved immediately without biasness, else biased resolution results in more frustration and demotivation among the employees and will convey wrong message to the employees who are not involved in such conflicts. Some kind of training is also required at initial level in the form of an orientation program or an induction program to let new joiners know that conflict kind of things are not acceptable at this place. If someone found guilty and reason behind any conflict should be penalized immediately to let other employees learn from it. Conflicts between workers and management should be resolved with the common concern, since employee oriented workplace generally exploits employees.

\section{LIMITATION}

The study is purely qualitative not the quantitative one and it considered only one aspect of conflict on employees but not the employer's effort to minimize it. The analysis was a generalized one which may vary from sector to 
sector, such as conflicts at banking sector may be very different from the education one i.e., in schools and colleges and so on. Thus, the types and strategy to handle conflicts vary from sector to sector.

\section{CONCLUSION}

Conflict at workplace is a common thing happens in every organization but it's the employer's job to not let the organization be affected from it. If the organization is already prepared to handle any kind of conflict without fail, the consequences could also be avoided. Its whole sole employer's competency that how he is able to tackle conflicts at workplace without affecting the productivity of the employees. Hence, unbiased, quick resolution is the most effective tool to settle conflict at workplace.

\section{REFRENCES}

[1] Bellet, Clement and De Neve, Jan-Emmanuel and Ward, George(2019), Does Employee Happiness have an Impact on Productivity?. Saïd Business School WP 2019-13, Available at SSRN: https://ssrn.com/abstract $=3470734$ or http://dx.doi.org/10.2139/ssrn.3470734.

[2] Claassen, R., \& Reimer, D. 2005, Conflict, collaboration, and change; LEAD p721. Unpublished manuscript, enter for Peace-making \& Conflict Studies, Fresno Pacific University, Fresno, California.

[3] Dontigney, E (2014). What Is Organizational Conflict; Retrieved from Azcentral: http://yourbusiness.azcentral. com/organizational-conflict-1227.html.

[4] Henry O. 2009, Organizational Conflict and its effects on Organizational Performance. Research Journal of Business Management,2 (1): 16-24.

[5] John-Eke, E. C., \& Akintokunbo, O. O. (2020). Conflict Management as a Tool for Increasing Organizational Effectiveness: A Review of Literature. International Journal of Academic Research in Business and Social Sciences, 10(5), 299-311.

[6] Kelly. (n.d.)2013; The Pros and Cons of Organizational Conflict. http://www.kellyservices.com.au/US/BusinessServices/Management-Tips/Apr-2012-Conflict/ \#.UyvOefmSx9w.

[7] Knippe, J. T and T. B Green 1999, Handling conflicts'. Workplace Learning11 (1), page no.26-32.

[8] Moore (2014), M. Employee Performance Appraisal. Retrieved fromSmall Business:

[9] Olu OJO\& Adensubomi Dupe Abolade (2014).Impact of Conflict Management on Employees' Performance in a public Sector Organization in Nigeria, Studies in Business and Economics, https://www.researchgate.net/publication/ 330202112_IMPACT_OF_CONFLICT_MANAGEMENT ON_EMPLOYEES \%27PERFORMANCE_IN_A_PUBLIC_SECTOR_ORGA NISATION_IN_NIGERIA

[10] Owizy S. 2012, - Effect Of Conflict Management On Bank Performance, A Case Study Of Keystone Bank Makurdill.

[11] Priyankdesh; Functional Conflicts, , august 20128 Pages, Retrieved March 21, 2014 from http://www.studymode. com/essays/Functional-Conflicts-1071330.html.

[12] Rana G., Sharma R., Goel A.K. (2019) Unraveling the Power of Talent Analytics: Implications for Enhancing Business Performance. In: Rajagopal, Behl R. (eds) Business Governance and Society. Palgrave Macmillan, Cham.

[13] Rana, G. and Sharma, R. (2019), "Emerging human resource management practices in Industry 4.0", Strategic HR Review, Vol. 18 No. 4, pp. 176-181. https://doi.org/ 10.1108/SHR-01-2019-0003.

[14] Rana, G., Sharma , R., Rana, S. (2017). The Use of Management Control Systems in the Pharmaceutical Industry. International Journal of Engineering Technology, Management and Applied Sciences. Volume 5, Issue 6, 12-23. 